\title{
Mulher mastectomizada e repercussões em seu cotidiano: verificação supletiva
}

\author{
Mastectomized woman and repercussions in their daily life: suppletive check \\ Mujer mastectomizada y repercusiones en su vida diaria: cheque supletivo
}

\section{Resumo}

O presente estudo tem como objetivo identificar, na literatura atual, as principais repercussões causadas pela mastectomia na vida das mulheres.Trata-se de uma revisão integrativa executada no segundo semestre de 2020 nas bases da Biblioteca Virtual de saúde. Foram incluídos artigos originais, em português, com texto completo disponível e publicados entre os anos de 2015 a 2020, totalizando uma amostra de 17 artigos. Como principais repercussões causadas pela mastectomia para cotidiano das mulheres podem ser citadas a diminuição de aspectos da qualidade de vida, da sexualidade, da autoestima e no enfrentamento do câncer. Foi possível entender, através dos estudos analisados, que a realização da mastectomia tem repercussões que vão além do sentido físico e fisiológico da pessoal; sua imagem enquanto membro de uma sociedade também é afetada, carecendo então de intervenções concretas. Constatou-se então que o enfermeiro deve estar atento ao bem- estar físico, mental e social da paciente para que assim possa executar uma assistência de qualidade.

Palavras-chave: Mastectomia; Qualidade de vida; Saúde da mulher.

\section{Abstract}

This study aims to identify, in the current literature, the main repercussions caused by mastectomy in women's lives. 
This is an integrative review carried out in the second half of 2020 on the basis of the Virtual Health Library. Original articles were included, in Portuguese, with full text available and published between the years 2015 to 2020, totaling a sample of 17 articles. As the main repercussions caused by mastectomy for the daily lives of women, the reduction in aspects of quality of life, sexuality, self-esteem and in the fight against cancer can be mentioned. It was possible to understand, through the analyzed studies, that the performance of mastectomy has repercussions that go beyond the physical and physiological sense of the person; their image as a member of a society is also affected, thus lacking concrete interventions. It was then found that the nurse must be aware of the patient's physical, mental and social wellbeing so that they can provide quality care.

Keywords: Mastectomy; Quality of life; Women's health.

\section{Resumen}

Este estudio tiene como objetivo identificar, en la literatura actual, las principales repercusiones de la mastectomía en la vida de las mujeres, se trata de una revisión integradora realizada en el segundo semestre de 2020 a partir de la Biblioteca Virtual en Salud. Se incluyeron artículos originales, en portugués, con texto completo disponible y publicados entre los años 2015 a 2020, totalizando una muestra de 17 artículos. Como principales repercusiones de la mastectomía en la vida diaria de las mujeres, se puede mencionar la reducción en aspectos de calidad de vida, sexualidad, autoestima y en la lucha contra el cáncer. Se pudo comprender, a través de los estudios analizados, que la realización de la mastectomía tiene repercusiones que van más allá del sentido físico y fisiológico de la persona; su imagen como miembro de una sociedad también se ve afectada, por lo que carecen de intervenciones concretas. Luego se encontró que la enfermera debe estar consciente del bienestar físico, mental y social del paciente para que pueda brindar una atención de calidad.

Palabras clave: Mastectomía; Calidad de vida; La salud de la mujer.

\section{Introdução}

O câncer de mama é caracterizado por uma desordem na multiplicação das células mamárias que sofreram alterações na estrutura de seu DNA. Este processo inicia a formação de tumor que pode ter caráter agressivo, invadindo tecidos adjacentes e levando ao comprometimento da funcionalidade do órgão (Guerra \& Miranda, 2019).

O Instituto Nacional de Câncer (INCA) estima o surgimento de 66.280 novos casos de câncer de mama no Brasil para o ano de 2020. Segundo esses dados, a doença representa 29,7\% das neoplasias malignas que acometem a população feminina. Apesar da existência de políticas públicas de saúde destinadas a prevenção e diagnóstico precoce, ainda decorre um número significativo de diagnósticos tardios, conhecimento insuficiente sobre as medidas de prevenção e negligência quanto a periodicidade dos exames de rotina, influenciando no grau de comprometimento funcional e mortalidade destas mulheres (Brasil, 2020).

Com o elevado número de diagnósticos tardios de tumores malignos, o tratamento cirúrgico mais indicado é a mastectomia, que se trata de um método que visa a retirada total ou parcial da glândula mamária, com o objetivo de reduzir o avanço do crescimento anormal das células. Vale ressaltar que os riscos desse procedimento são maiores em pessoas que fazem a cirurgia com idade e grau da doença avançada (Volkmer, 2019).

O processo desencadeado pela doença, bem como reflexo do tratamento geram mudanças significativas na vida da paciente. Os aspectos emocionais e físicos são os que mais alteram durante o tratamento. No entanto o fator social também apresenta um destaque importante. Na maioria dos casos levam-se anos para adaptação à nova rotina, bem como na forma com que a mulher se vê como indivíduo, o que pode acarretar em um distanciamento social nocivo (Pereira, 2019).

A inatividade no pós-operatório pode levar ao comprometimento gradual da força muscular e da flexibilidade, podendo assim prejudicar o grau de amplitude dos movimentos, o que desencadeia processo álgico local. Tal acometimento está diretamente relacionado com a redução do bem-estar físico e emocional, e com a redução do desempenho para realização das atividades da vida diária ou mesmo de convívio social, bem como à qualidade de vida (Rocha, 2019).

Os profissionais de saúde possuem papel fundamental nos cuidados pós-operatório, a fim de fornecer subsídio e orientação que favoreçam a readaptação da funcionalidade destas mulheres às suas atividades rotineiras, observando possíveis interferências a recuperação (Galdino, 2017). 
Logo, percebeu-se que há necessidade de compilar as informações disponíveis na literatura atual sobre as principais repercussões da mastectomia no cotidiano das mulheres, a fim de subsidiar planejamentos assistenciais, visto ao impacto individual e social decorrente da doença.

Deste modo, o presente estudo teve como objetivo identificar, na literatura atual, as principais repercussões causadas pela mastectomia na vida das mulheres.

\section{Metodologia}

\subsection{Tipo de estudo}

Tratou-se de uma revisão integrativa que é um método que proporciona a síntese e acúmulo de conhecimento existente sobre o tema em questão a partir da sistematização e análise dos resultados, o que proporciona um método mais imediato de aplicabilidade do referido estudo, visando melhorar cada vez mais o desempenho das diversas áreas de conhecimento.

O método de revisão integrativa da literatura representa ainda uma edificação extensas análises da literatura, colaborando com discussões acerca de métodos e resultados das pesquisas, contribuindo também para novas reflexões quanto a execução de pósteros estudos (Mendes, 2008).

A questão norteadora dessa pesquisa foi formulada através da inserção de palavras essenciais a fim de possibilitar a localização dos estudos primários, que abordassem o tema proposto, disponíveis nas bases de dados, sendo ela: Quais repercussões a mastectomia no cotidiano das mulheres?

\subsection{Local de estudo}

A busca dos estudos primários foi realizada nas seguintes bases de dados, indexadas na Biblioteca Virtual em Saúde (BVS): Literatura Latino-americana e do Caribe em Ciências da Saúde (LILACS), INDEX Psicologia e Base de Dados em Enfermagem (BDENF).

\subsection{Participantes do estudo}

Foram incluídos artigos originais, em português, com texto completo disponível e publicados entre os anos de 2015 a 2020. Excluíram-se artigos duplicados e aqueles que não apresentavam relação direta com a questão norteadora e com os objetivos desse estudo, bem como teses e dissertações. Dessa forma, chegou-se ao total de 17 publicações aptas a participarem deste estudo.

\subsection{Coleta de dados}

Na coleta de dados foram utilizados os descritores pesquisados em Descritores em Ciências da Saúde (DeCS) como: Mastectomia, Qualidade de vida e Saúde da mulher.

Procedeu-se a leitura minuciosa de cada resumo/artigo, destacando aqueles que responderam ao objetivo proposto por este estudo, bem como os critérios de inclusão. Em seguida, foi realizada a leitura completa dos artigos selecionados para a organização e tabulação dos dados, por meio de instrumento de coleta de dados contendo: título, ano de publicação, base de dados e principais achados.

\subsection{Análise de dados}

Durante a análise crítica dos artigos, foram agrupados os conteúdos por similaridade para formação das categorias de discussão dos resultados. Por fim, foi apresentada de forma clara a evidência encontrada. 


\subsection{Aspectos éticos}

A presente revisão integrativa assegurou os aspectos éticos, garantindo a autoria dos artigos pesquisados, utilizando para citações e referências dos autores as normas da Associação Brasileira de Normas Técnicas (ABNT). Sendo devidamente conduzida no sentido de não plagiar trabalhos. E por se tratar de uma revisão integrativa é dispensável a utilização do Termo de Consentimento Livre e Esclarecido (TCLE).

\section{Resultados}

Após a seleção, os artigos foram submetidos a um instrumento de coleta a fim de serem retiradas as principais informações das obras (Apêndice A). A partir dessa coleta de informações, os resultados e os principais achados foram agrupados para facilitar o entendimento, como demonstrado no Quadro 1.

Quadro 1 - Resultados e principais achados de artigos estudados.

\begin{tabular}{|c|c|c|c|c|}
\hline & Título do Artigo & $\begin{array}{l}\text { Ano de } \\
\text { publica } \\
\text { ção }\end{array}$ & $\begin{array}{l}\text { Base de } \\
\text { dados }\end{array}$ & Principais achados \\
\hline 01 & $\begin{array}{l}\text { Enfrentamento de mulheres diante do } \\
\text { tratamento Oncológico e da mastectomia } \\
\text { como repercussão do câncer de mama }\end{array}$ & 2020 & BDENF & $\begin{array}{l}\text { O processo de enfrentamento é uma tarefa árdua } \\
\text { sendo que cada mulher enfrenta esse processo de } \\
\text { maneira diferenciada. }\end{array}$ \\
\hline $\mathbf{0 2}$ & $\begin{array}{l}\text { Sexualidade de mulheres submetidas à } \\
\text { mastectomia: Identificação das fases } \\
\text { afetadas nociclo da Resposta sexual }\end{array}$ & 2020 & BDENF & $\begin{array}{l}\text { Os profissionais de saúde em geral devem estar } \\
\text { atentos para a ocorrência dessas modificações na } \\
\text { vida dessa mulher, diante do todo o processo, desde } \\
\text { diagnóstico, no tratamento e readaptação, para dessa } \\
\text { forma contribuir para o cuidado integral. }\end{array}$ \\
\hline $\mathbf{0 3}$ & $\begin{array}{l}\text { Perfil epidemiológico de mulheres } \\
\text { mastectomizadas em um serviço de } \\
\text { referência localizado no Vale } \\
\text { do Taquari/RS }\end{array}$ & 2019 & LILACS & $\begin{array}{l}\text { Identificou-se mulheres de maioria branca, com } \\
\text { baixa escolaridade, na faixa etária superior a } 50 \text { anos, } \\
\text { provenientes de } 29 \text { municípios da região estudada }\end{array}$ \\
\hline 04 & $\begin{array}{l}\text { Câncer de mama e imagem corporal: } \\
\text { impacto dos tratamentos no olhar de } \\
\text { Mulheres mastectomizadas }\end{array}$ & 2019 & LILACS & $\begin{array}{l}\text { O cuidado com a saúde das mulheres acometidas } \\
\text { pela doença demanda assistência multiprofissional, } \\
\text { que auxilie no processo de enfrentamento do câncer } \\
\text { e na reabilitação }\end{array}$ \\
\hline 05 & $\begin{array}{l}\text { Qualidade de vida eresultado estético } \\
\text { após mastectomia ereconstrução } \\
\text { mamária }\end{array}$ & 2019 & LILACS & $\begin{array}{l}\text { A qualidade de vida das pacientes no período } \\
\text { posterior à reconstrução mamária com implantes } \\
\text { mamários é superior em relação ao período anterior } \\
\text { ao procedimento cirúrgico. }\end{array}$ \\
\hline 06 & $\begin{array}{l}\text { Percepção das Mulheres sobre sua } \\
\text { Funcionalidade e Qualidade de Vida } \\
\text { após Mastectomia }\end{array}$ & 2018 & LILACS & $\begin{array}{l}\text { Após o tratamento, as pacientes elataram melhora da } \\
\text { capacidade funcional, emocional e autoestima, } \\
\text { possibilitando sua reinserção social e retorno às } \\
\text { atividades de vida diária. }\end{array}$ \\
\hline 07 & $\begin{array}{l}\text { Representações Sociais sobre o Corpo e } \\
\text { Satisfação Sexual de Mulheres } \\
\text { mastectomizadas e seus parceiros }\end{array}$ & 2018 & LILACS & $\begin{array}{l}\text { O corpo mastectomizado possuiu mais } \\
\text { representações negativas vinculadas à aparência da } \\
\text { mama, impactando no nível de satisfação sexual do } \\
\text { casal, onde se constatou que este diminui após a } \\
\text { mastectomia, interferindo na autoimagem e na vida } \\
\text { conjugal. }\end{array}$ \\
\hline 08 & $\begin{array}{l}\text { Sentimentos vivenciados pelas mulheres } \\
\text { mastectomizadas }\end{array}$ & 2018 & BDENF & $\begin{array}{l}\text { A perda da mama acarretou em prejuízos físicos, } \\
\text { porém, a forma como cada uma passou pelo processo } \\
\text { de adoecimento e tratamento estava associada aos } \\
\text { significados que atribuíram a doença. }\end{array}$ \\
\hline
\end{tabular}




\begin{tabular}{|c|c|c|c|c|}
\hline 09 & $\begin{array}{l}\text { Qualidade de vida de mulheres } \\
\text { mastectomizadas matriculadas em um } \\
\text { programa de reabilitação }\end{array}$ & 2017 & BDENF & $\begin{array}{l}\text { Mulheres mais jovens, sem reconstrução da mama, } \\
\text { casadas e em tratamento de } \\
\text { quimioterapia ou hormonioterapia apresentaram } \\
\text { maiores perdas da qualidade de vida. }\end{array}$ \\
\hline 10 & $\begin{array}{l}\text { Câncer de mama: arepercussão da } \\
\text { mastectomia no psiquismo da mulher }\end{array}$ & 2017 & LILACS & $\begin{array}{l}\text { As repercussões psicológicas variam de acordo com } \\
\text { a fase do adoecimento e da Subjetividade de cada } \\
\text { participante. }\end{array}$ \\
\hline 11 & $\begin{array}{l}\text { Tempo sentado, imagem corporal e } \\
\text { qualidade de vida em mulheres após a } \\
\text { cirurgia do câncer de mama. }\end{array}$ & 2017 & LILACS & $\begin{array}{l}\text { O tipo de cirurgia pode influenciar o tempo sentado } \\
\text { e aspectos da imagem corporal e da qualidade de } \\
\text { vida, com piores escores para as mulheres } \\
\text { submetidas à cirurgia radical. }\end{array}$ \\
\hline 12 & $\begin{array}{l}\text { Avaliação precoce da qualidade de vida } \\
\text { eautoestima de pacientes } \\
\text { mastectomizadas submetidas ou não } \\
\text { àreconstrução mamária }\end{array}$ & 2017 & LILACS & $\begin{array}{l}\text { Mulheres mastectomizadas com ou sem } \\
\text { reconstrução mamária após um mês da cirurgia não } \\
\text { apresentaram repercussões na qualidade de vida e } \\
\text { na autoestima, quando comparadas entre si, bem } \\
\text { como comparadas às mulheres sem história de } \\
\text { câncer. }\end{array}$ \\
\hline 13 & $\begin{array}{l}\text { Mulher mastectomizada por câncer de } \\
\text { mama: vivência das atividades } \\
\text { cotidianas }\end{array}$ & 2017 & BDENF & $\begin{array}{l}\text { Após o procedimento, Relataram dificuldades para } \\
\text { ações de autocuidado, trabalho e tarefas domésticas. } \\
\text { Adoção de estratégias de enfrentamento foi } \\
\text { necessária para vencer as barreiras cotidianas. }\end{array}$ \\
\hline 14 & $\begin{array}{l}\text { Sentimentos de mulheres com câncer de } \\
\text { mamaapós mastectomia }\end{array}$ & 2017 & BDENF & $\begin{array}{l}\text { Os sentimentos vivenciados pelas participantes a } \\
\text { princípio são de surpresa e de desespero diante da } \\
\text { doença, e quando se deparam com a mastectomia } \\
\text { como forma de tratamento, surgem tristeza, negação, } \\
\text { depressão, ansiedade e, por fim, a aceitação. }\end{array}$ \\
\hline 15 & $\begin{array}{l}\text { Aspectos que podem influenciar a } \\
\text { qualidade de vida da mulher } \\
\text { mastectomizada. }\end{array}$ & 2016 & INDEX & $\begin{array}{l}\text { Conhecer fatores que influenciam na qualidade de } \\
\text { vida da mulher mastectomizada favorece uma } \\
\text { melhora na prática do cuidado por fortalecer ações } \\
\text { específicas, colaborando com a qualidade de vida } \\
\text { dessas mulheres. }\end{array}$ \\
\hline 16 & $\begin{array}{l}\text { Qualidade de vida e cuidado de } \\
\text { enfermagem na percepção de mulheres } \\
\text { mastectomizadas }\end{array}$ & 2015 & BDENF & $\begin{array}{l}\text { Para a mastectomizada, qualidade de vida está ligada } \\
\text { a ter saúde, alimentação saudável, paz, } \\
\text { espiritualidade, trabalho e atividade física. }\end{array}$ \\
\hline 17 & $\begin{array}{l}\text { Autoestima e qualidade de vida de } \\
\text { mulheres submetidas à cirurgia } \\
\text { Oncológica de mama }\end{array}$ & 2015 & BDENF & $\begin{array}{l}\text { Existe influência da autoestima na qualidade de vida } \\
\text { de mulheres com câncer de mama em pós-operatório } \\
\text { tardio e há certos traços que permitem identificar } \\
\text { aquelas que terão dificuldade para enfrentar o } \\
\text { câncer. }\end{array}$ \\
\hline
\end{tabular}

Fonte: Elaboração própria.

No Gráfico 1, estão dispostos os artigos de acordo com o ano em que foram publicados. Destaca-se o ano de 2017 como tendo o maior número de publicações, 06 (35,29\%). 
Gráfico 1 - Artigos em relação ao ano de publicação.

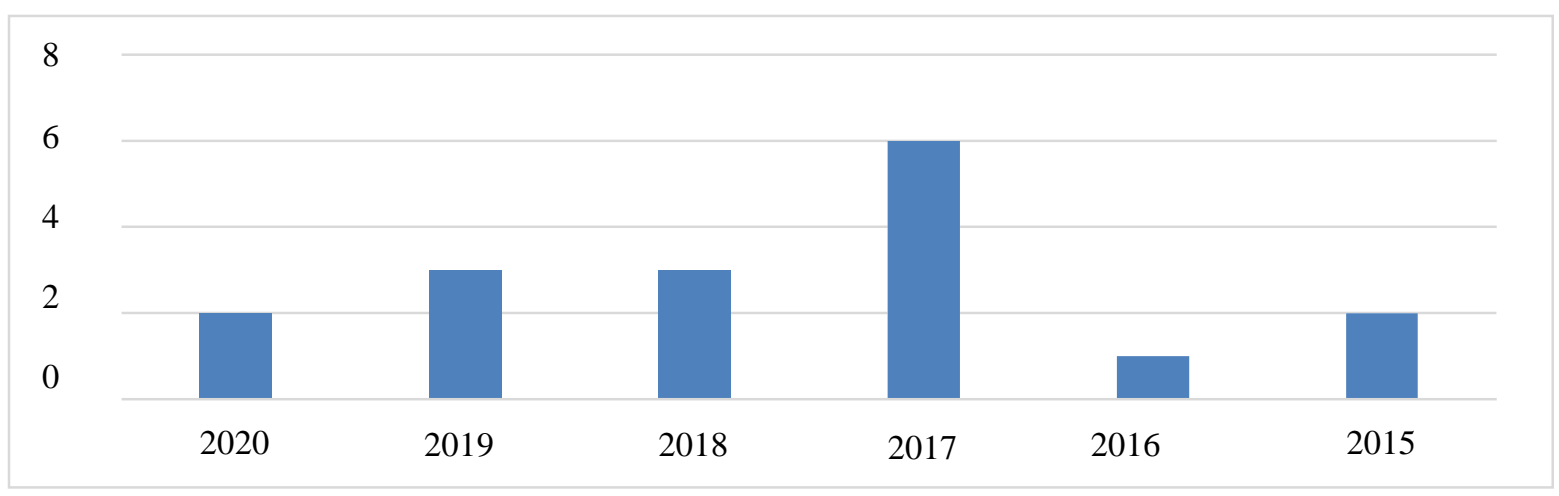

Fonte: Elaboração própria.

Quanto às bases de dados, percebeu-se igualdade entre a base BDENF e a LILACS, ambas com 08 (47,05\%) artigos indexados, como demonstrado no no Gráfico 2. Nota-se também 01 artigo (5,9\%) presente na base INDEX Psicologia, demonstrando que a qualidade de vida das mulheres mastectomizadas é um assunto discutido de forma multidisciplinar, envolvendo também profissionais fora da área da enfermagem.

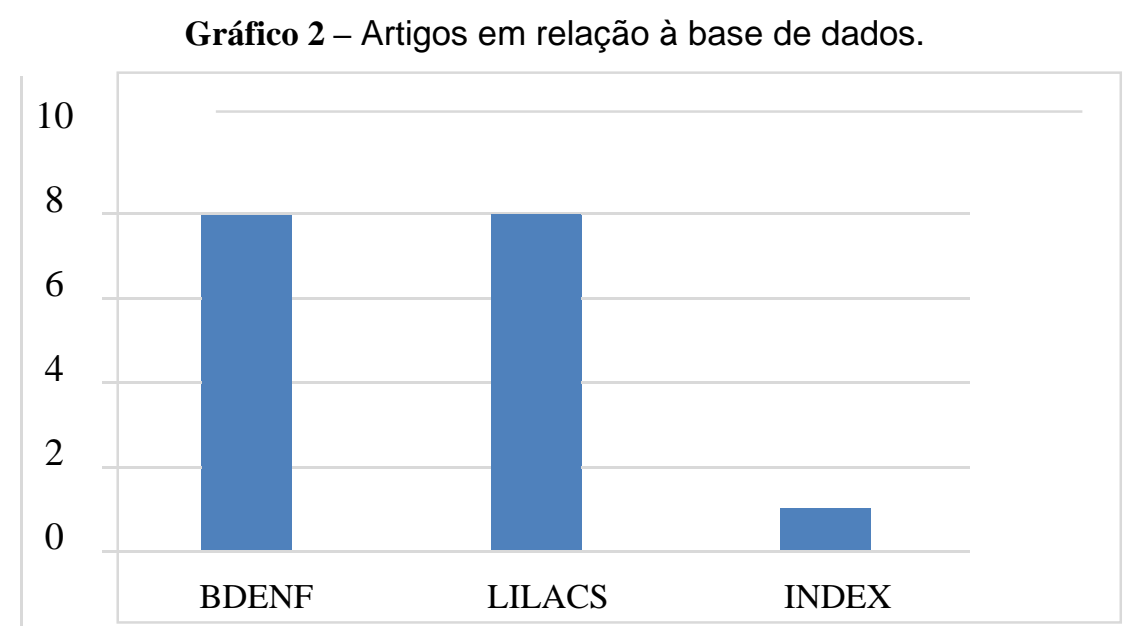

Fonte: Elaboração própria.

Os artigos foram agrupados também de acordo com as sub-temáticas abordadas por cada um. Dessa forma, a discussão dos resultados pode ser feita de forma mais clara e sistemática. As quatro categorias divididas foram: Repercussões na qualidade de vida, Repercussões na sexualidade, Repercussões na auto estima e Repercussões para o enfrentamento do câncer, como mostra o Gráfico 3. 
Gráfico 3 - Categorias para discussão dos artigos.

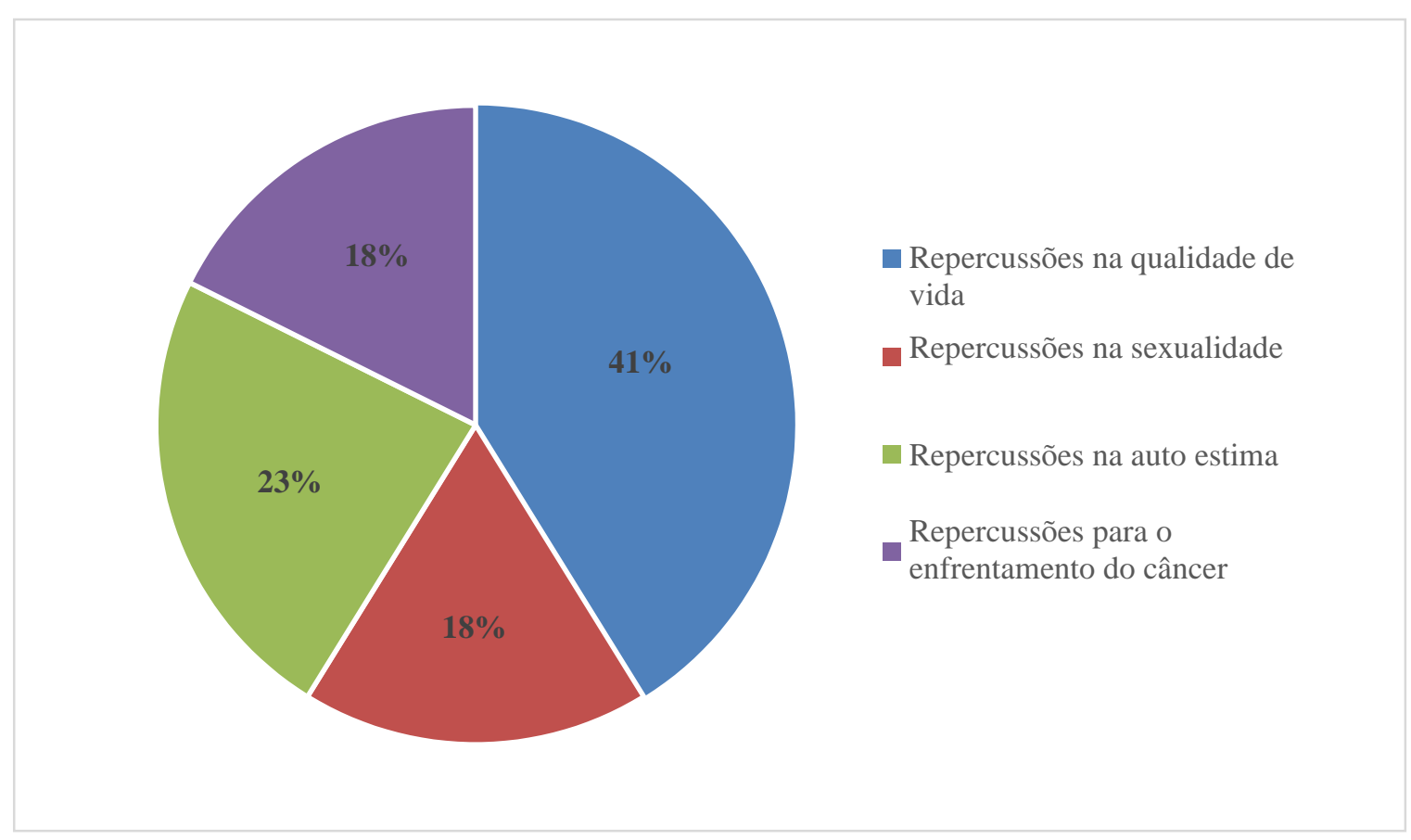

Fonte: Elaboração própria.

\section{Discussão}

\subsection{Repercussões na qualidade de vida}

A retirada da mama tem forte influência sobre a qualidade de vida da mulher com câncer de mama. É percebido que o sentimento de medo da morte e da doença repercutem negativamente na qualidade de vida, principalmente pela incerteza do que pode acontecer com a evolução da doença. Entender fatores que repercutem na qualidade de vida da mulher mastectomizada permite executar uma melhor prática do cuidado prestado pela enfermagem (Almeida, 2016).

Percebe-se que a maioria das mulheres vivenciam emoções negativas em resposta à mastectomia. A tristeza ao perder a mama é algo impossível de se evitar, visto que ela é o símbolo da maternidade, sexualidade e sensualidade. As mulheres sentem-se mutiladas e desfiguradas. Em contrapartida, a minoria sentem alívio após realizar a cirurgia, pois, apesar da perca mamária, retirou-se o tumor que tanto lhe comprometia a vida, ou seja, a mastectomia lhes mostravam esperança da cura (Lima, 2018).

Para a mulher mastectomizada, a qualidade de vida está ligada a ter saúde, alimentação saudável, paz, espiritualidade, trabalho e atividade física. Em seu estudo feito no ambulatório de mastologia de uma maternidade-escola na cidade de Fortaleza$\mathrm{CE}$, foi observado também que o cuidado de enfermagem envolve teoria e técnica, sendo necessário cuidar de forma holística e ética, respeitando aspectos culturais e sociais. É perceptível então a necessidade de um atendimento humanizado à essas pacientes, garantindo uma assistência menos mecanizada, porém sem perder o escopo de ajudar a paciente da melhor forma possível (Almeida, 2015).

Em consonância com essa idéia de cuidado humanizado afim de garantir a qualidade de vida da mulher e acerca da importância do atendimento psicológico à essas pacientes, faz-se necessário o acompanhamento da saúde mental da paciente mastectomizada, com o intuito de minimizar os impactos ocasionados pela retirada da mama. Para tanto, a assistência deve ser voltada para a melhora da qualidade de vida em toda a sua amplitude (Vale, Dias \& Miranda, 2017).

A estética também é um importante fator repercussor na qualidade de vida da mulher após a mastectomia. Ocorreu uma evolução na satisfação pessoal e na qualidade de vida das mulheres que fizeram o processo de reconstrução mamária. Apesar da 
sensação de mutilação e do trauma vivenciado pela mastectomia, a reconstrução de mama, quando bem executada, pode trazer excelentes resultados estéticos. Em consequência, a mulher passa adquirir sentimentos de autoconfiança e bem-estar com sua imagem (Cammarota, 2019).

\subsection{Repercussões na sexualidade}

Existe influência na sexualidade de mulheres com câncer de mama em pós- operatório tardio e há certos traços que permitem identificar aquelas que terão dificuldade para enfrentar sua condição atual. Percebe-se que a perda mamária representa um fator de impacto muito grade na forma como a paciente se enxerga como mulher. Este impacto, se não trabalhado, pode gerar uma ansiedade e, possivelmente, sintomatologia depressiva (Gomes, Soares \& Silva, 2015).

Os profissionais de saúde em geral devem estar atentos para a ocorrência de modificações na vida sexual da mulher mastectomizada durante todo o processo, desde diagnóstico, no tratamento e readaptação, para dessa forma contribuir para o cuidado integral. Isso contribui para a visão de que os cuidados de saúde devem ser executados de maneira holística, englobando todos os aspectos do desenvolvimento feminino (Martins, 2020).

A abordagem da questão sexual pelos profissionais de enfermagem que assistem as mulheres que vivenciam o contexto de adoecimento por câncer de mama contribuem para uma melhor percepção das mudanças ocorridas e na readaptação na rotina de vida, facilitando o cuidado integral, visando, ainda, minimizar os danosdesenvolvidos por todo o processo do tratamento (Boing, 2017 \& Fireman, 2018).

\subsection{Repercussões na autoestima}

O impacto ocasionado pelo câncer de mama vai além da dor e do desconforto decorrentes da doença e de seu tratamento. Frequentemente, ocorrem também mudanças de ordem psíquica, social e econômica. As dimensões físicas do câncer revelam um cenário favorável para a estigmatização e ao afastamento do paciente oncológico do convívio social, devido aos efeitos do tratamento, e até mesmo ao afastamento de membros da família por preconceito. Tais fatores podem abalar a autoestima da paciente, gerando consequências danosas à saúde mental (Silva Arboit, Menezes, 2020).

A mama é vista na atual sociedadecomo um símbolo corpóreo da sexualidade, feminilidade e ligada à construção da identidade da mulher, o que leva a pensar que qualquer patologia que ameace este órgão leva a uma perda da autoestima e alteração na sua autoimagem, acarretando sentimentos de inferioridade e rejeição. Algumas mulheres acometidas pelo câncer de mama tendem a perceber e representar seus corpos como mutilados, adotando uma visão sobre si de algo anormal e deficiente (Hirschle, 2018).

As mulheres com baixa autoestima após a mastectomia se mostraram afetadas com este procedimento envolvendo os aspectos físico e emocional em sua identidade feminina, além de demonstrarem a necessidade de compartilhar suas experiências em um momento tão delicado, despertando a empatia, frente aos obstáculos por elas vivenciados (Alvez, 2017).

O cuidado com a saúde das mulheres acometidas pela doença demanda assistência multiprofissional auxilia no processo de enfrentamento do câncer e na reabilitação para além das limitações físicas. Busca-se dessa forma a reconexão do corpo físico, psíquico e espiritual, visando facilitar a adaptação ao "novo corpo" e permitir incremento na autoestima, a reinserção social e melhoria da qualidade de vida (Oliveira, 2019).

\subsection{Repercussões para o enfrentamento do Câncer}

Cada mulher é capaz de se adaptar às diferentes condições impostas pela doença e pela cirurgia, mesmo passando por situações adversas durante todo o processo. $\mathrm{O}$ apoio da família, amigos, a fé e a disponibilidade dos serviços de saúde auxiliam a mulher a adaptar-se às alterações decorrentes da mastectomia, servindo de fatores protetórios no enfrentamento da mudança 
física (Dias, 2017).

É de suma importância a realização de intervenções que promovam melhor qualidade de vida a essas pacientes, com atuação interdisciplinar eficaz por parte da equipe de saúde. Em sua pesquisa, constataram que mulheres mais jovens, sem reconstrução da mama, casadas e em tratamento de quimioterapia ou hormonioterapia apresentaram maiores dificuldades no enfrentamento da doença, o que cria um alerta para este público (Galdino, 2017).

Apesar de algumas dificuldades fazerem parte do processo de adaptação das mastectomizadas, a mulher pode ainda encontrar caminhos para superá-las, por meio das mais variadas maneiras. Tais estratégias contribuem para que o enfrentamento da doença ocorra de maneira mais eficaz, tendo em vista que quando a mulher tem uma rede de apoio sólida fica mais fácil encarar novos desafios, o que contribui significativamente no tratamento (Lena, 2019).

\section{Considerações Finais}

O presente estudo abordou as principais consequências da cirurgia de mastectomia para o convívio social da mulher. Foi possível entender, através dos estudos analisados, que a realização da mastectomia tem repercussões que vão além do sentido físico e fisiológico da pessoal; sua imagem enquanto membro de uma sociedade também é afetada, carecendo então de intervenções concretas.

Como principais repercussões causadas pela mastectomia para cotidiano das mulheres podem ser citadas a diminuição de aspectos da qualidade de vida, da sexualidade, da autoestima e no enfrentamento do câncer. Vale ressaltar que esses fatores podem ser alterados em quantidade e intensidade dependendo da rede de apoio da paciente e de sua própria resiliência para o enfrentamento da situação.

Constatou-se então que o enfermeiro deve estar atento ao bem-estar físico, mental e social da paciente para que assim possa executar uma assistência de qualidade. Ressalta-se também a importância de diagnósticos de enfermagem precisos e elaborados de acordo com as individualidades de cada paciente, garantindo que os cuidados sejam executados da melhor forma possível.

Fica nítido que existe a necessidade de que a formação em saúde mental seja continuada e permanente, sugerimos a realização de novos estudos eficazes para as atividades do enfermeiro em busca de novos saberes e práticas quanto a saúde mental dos pacientes.

\section{Referências}

Almeida, N. G., et al. (2016). Aspectos Que Podem Influenciar A Qualidade De Vida Da Mulher Mastectomizada. Cienc Cuid Saude. 15(3), $452-459$.

Almeida, N. G. et al. (2015). Qualidade De Vida E Cuidado De Enfermagem Na Percepção De Mulheres Mastectomizadas. Rev Enferm UFSM. 5(4), 607-617.

Alves, V. L. et al. (2017). Avaliação precoce da qualidade de vida e autoestima de pacientes mastectomizadas submetidas ou não à reconstrução mamária. Rev. Bras. Cir. Plást. 32(2), p.208-217, 2017.

Boing, L., et al. (2017). Tempo sentado, imagem corporal e qualidade de vida em mulheres após a cirurgia do câncer de mama. Rev Bras Med Esporte. 23(5). Brasil. Ministério da Saúde. (2020). Estatísticas de Câncer. Ministério da Saúde.

Cammarota, M. C., et al. (2019). Qualidade de vida e resultado estético após mastectomia e reconstrução mamária. Rev. Bras. Cir. Plást. 34(1), 45-57.

Dias, L. V., et al. (2017). Mulher mastectomizada por câncer de mama: Vivência das atividades cotidianas. Revista Cuidado é Fundamental. 9(4), 1074-1080.

Fireman, K. M., et al. (2018). Percepção das Mulheres sobre sua Funcionalidade e Qualidade de Vida após Mastectomia. Revista Brasileira de Cancerologia. 64(4), 499-508.

Galdino, A. R., et al. (2017). Qualidade de vida de mulheres mastectomizadas matriculadas em um programa de reabilitação. Revista Cuidado é Fundamental. $9(2), 451-458$.

Gomes, N. S., Soares, M. B. O., \& Silva, S. R. (2015). Autoestima e qualidade de vida de mulheres submetidas à cirurgia oncológica de mama. Rev Min Enferm. 19(2), 120-126. 
Research, Society and Development, v. 10, n. 11, e535101119966, 2021

(CC BY 4.0) | ISSN 2525-3409 | DOI: http://dx.doi.org/10.33448/rsd-v10i11.19966

Guerra, I., \& Miranda, L. S. (2019). Juciane. Impacto da mastectomia radical na sexualidade feminina. Revista da Faculdade União Goyazes, Trindade/GO. 13(2).

Hirschle, T. M. R., et al. (2018). Representações Sociais sobre o Corpo e Satisfação Sexual de Mulheres Mastectomizadas e seus Parceiros. Temas em Psicologia. 26(1), 457- 468 .

Lena, P. T., et al. (2019). Perfil epidemiológico de mulheres mastectomizadas em um serviço de referência localizado no Vale do Taquari/RS. Revista de Epidemiologia e Controle de Infecção, Santa Cruz do Sul. 9(2).

Lima, M. M. G., et al. (2018). Sentimentos vivenciados pelas mulheres mastectomizadas. Rev enferm UFPE on line, Recife. 12(5), 1216-24.

Martins, J. O. A., et al. (2020). Sexualidade de mulheres submetidas à mastectomia: identificação das fases afetadas no ciclo da Resposta sexual. Revista Cuidado é Fundamental. 12(1), 67-72.

Mendes, K. D. S. (2008) Revisão integrativa: método de pesquisa para a incorporação de evidências na saúde e na enfermagem. Texto contexto - enferm. 17 (4).

Oliveira, T. M., et al. (2019). Câncer de mama e imagem corporal: impacto dos tratamentos no olhar de mulheres mastectomizadas. Saúde e Pesquisa. 12(3), 451-462.

Pereira, S. F. M. E. (2019). Mastectomia e mamoplastia na vida das mulheres com câncer de mama. Revista Caderno de Medicina. 2(1), 42-58.

Rocha, C. B., et al. (2019). Sentimentos de mulheres submetidas à mastectomia total. Rev. Cuidart. 10(1).

Souza, M. T., Silva, M. D., \& Carvalho, R. (2010). Revisão integrativa: o que é e como fazer. Revista Einstein, São Paulo. 8(1), 102-106.

Silva, F. C. N., Arboit, E. L., \& Menezes, L. P. (2020). Enfrentamento de mulheres diante do tratamento oncológico e da mastectomia como repercussão do câncer de mama.

Revista Cuidado é Fundamental. 12(1), 357-363..

Vale, C. C. S. O., Dias, I. C., \& Miranda, K. M. (2017). Câncer de mama: a repercussão da mastectomia no psiquismo da mulher. Mental, Barbacena-MG. 11(21), 527- 545 .

Volkmer, C. (2019). Reconstrução mamaria sob a ótica de mulheres submetidas a mastectomia: Uma metaetnografia. Texto \& Contexto Enfermagem, Florianópolis/SC. 28(2), 1-17 